\title{
The Effectiveness of Instruction-Oriented Hypertext Systems Compared to Direct Instruction in e-learning Environments
}

\author{
Chokri Barhoumi \\ Taibah University, Kingdom of Saudi Arabia \\ Pier Giuseppe Rossi \\ University of Macerata, Italy
}

\begin{abstract}
The use of hypertext systems for learning and teaching complex and ill-structured domain of knowledge has been attracting attention in design of instruction. In this context, an experimental research has been conducted to explore the effectiveness of instructional design oriented hypertext systems. Cognitive flexibility hypertext theory is compared to direct instruction course design without hypertext systems for teaching and learning Flash online course in e-learning environment. Researchers used an experimental approach conducted in the academic year 2010 with independent sample of students of an experimental group (73 students) compared to a control group (73 students) from a university class. The results show the effectiveness of the hypertext systems course design compared to direct online course design. Indeed, the results of cognitive performance have demonstrated that the average time to answer achievement tests is lower for flexible instruction compared to average time for direct instruction. The number of students' accesses to learning resources in the e-learning platform is higher in case of flexible instruction compared to direct instruction. Results of the experimentation also demonstrate that there are significant differences between the experimental group and the control group, regarding the attitudes of students toward using flexible online course design based cognitive flexibility hypertext theory and direct online course design.
\end{abstract}

Keywords: E-learning; Online teaching; Flexible online course design; Direct online course design; Cognitive flexibility; Hypertext systems

\section{Introduction}

The World Wide Web service has become one of the most important means to provide online learning resources for learners in educational institutions to share and obtain information (Richard \& Haya, 2009). The information and communication technologies shared between learners through different applications (online discussion, Web 2.0 etc.) profoundly enhance communication opportunities. As part of new technologies, the Internet is one of the fastest and most effective ways of communication between learners and online learning resources. Compared to traditional ways of communication, Internet-based communication facilitates access to learning resources in either synchronous or asynchronous way (Zengin, Arikan, \& Dogan, 2011).

E-learning is a concept that is covering a variety of applications, processes, and learning methods. It is also referring to the use of information and communication technologies to 
facilitate the access to online learning/teaching resources and to provide online learners with collaborative environments and Web 2.0 applications. The latter offers a set of tools and utilities affecting communication and its social impact (Rossi, 2009). E-learning is based on Open Educational Resources (OER) with sharing and reusing digital materials, created within a practising teachers and students community in accordance with the aims of the open access movement (Banzato, 2012).

The online learning environments are not seen merely as tools to support learning. They are components of a wider approach that is more "theoretic" (Rossi et al., 2010). A well-structured learning environment has to facilitate the user in connection with different tools in order to build, to share and to change his/her level of knowledge (Rossi, 2006).

The design of the e-learning process has a cognitive importance for learners in the learning environment. Hereby, the e-learning process must favor cognitive flexibility (Spiro, 1996) and has to foster knowledge acquisition for learners in the context of e-learning.

Generally, there are online course designs which favor learning and guarantee the acquisition of knowledge by learners. However, some other online course designs favor less learning. Thus, design of the online instruction adopted in the e-learning process has an impact on the effectiveness of learning (Spiro et al., 1996).

The aim of the present experimental research is to test if flexible instruction based cognitive flexibility hypertext theory (Spiro, 1996) is effective for learning compared to direct instruction without hypertext systems for the design of an online course. The effectiveness is measured in the present experimental study through criteria of cognitive performance and attitudes of students toward direct and flexible online course design.

\section{Theoretical Framework}

\section{The Cognitive Flexibility Theory}

The cognitive flexibility theory (CFT) is a constructivist learning theory inspired from a metaphor proposed by Wittgenstein (Wittgenstein, 1953). According to this theory, the learning process must be designed in long and in large and conceived in great detail (crisscrossing) and then must provide possibilities to students to acquire knowledge and navigate with flexible and rapid manner in online learning resources.

The cognitive flexibility theory is a theory of designing instruction of case-based learning proposed by Spiro and his co-workers to address problems associated with the acquisition and transfer of complex and ill-structured domain of knowledge (Spiro et al., 1988).

A central theme of cognitive flexibility theory is the fact that simplification of complex and illstructured domain of knowledge with applications of hypertext systems to design learning material is a significant contributing factor to many examples of effective learning and teaching (e.g. Coulson, Feltovich, \& Spiro, 1989; Feltovich et al., 1989; Myers, Feltovich, Coulson, Adami, \& Spiro, 1990; Spiro et al., 1988; Spiro, Vispoel, Schmitz, Samarapungavan, \& Boerger, 1987). In fact, ill-structured and complex knowledge domains are comprised of many concepts that are relevant in a typical knowledge application situation and where the 
application of a concept or combination of concepts can vary widely across different case situations (Spiro et al., 1988; for a discussion, see Jacobson \& Spiro, 1991).

CFT is based on the hypothesis which claims that the acquisition of ill-structured and complex knowledge is more effective when there is an exposure of students multiple times within the same learning situations. In fact, students face complexity of learning situation more easily and with necessary mental developments but according to different perspectives with application of hypertext systems to educational situations (Feltovich et al., 1989; Spiro et al. 1988; Spiro, Vispoel, Schmitz, Samarapungavan, \& Boerger, 1987). Covering domain of knowledge with different viewpoints, multiple representations of knowledge, and connecting abstract concepts with case studies allow an effective learning (Jacobson et al., 1995).

CFT proposes a number of instructional principles that are intended to simplify complex and illstructured knowledge domains and to make educational material cognitively tractable. There are five instructional principles guiding the application of CFT in a learning environment. These instructional principles are applied in present study to explore the effectiveness of online educational material based CFT and using hypertext systems compared to direct online course design without any hypertext systems.

The five principles of CFT are:

(1) Multiple knowledge representations: In general, the use of uni-dimensional depiction of complex and ill-structured knowledge don't simplify the acquisition of knowledge by students and misrepresents important conceptual facets of the domain (Spiro et al., 1987; Spiro et al., 1988). CFT recommends the use of multiple ways to represent knowledge in the learning process (e.g. multiple themes, multiple analogies, multiple intellectual points of view) to reflect more accurately the multifaceted nature of complex knowledge. The cognitive flexibility hypertext theory as suggested by Jacobson and Spiro $(1993,1995)$ generally provides multiple representations of the same knowledge to be acquired by learners and allows for them necessary mental developments for treatment of information.

(2) Linking and tailoring abstract concepts to different case examples in the learning process with application of hypertext systems: In ill-structured knowledge domains, there is a considerable variability in terms of how abstract concepts apply to actual case situations. In the aim of showing knowledge us as "knowledge-in-use, CFT recommends designing abstract concepts with using multiple case examples to demonstrate to the learner the nuances of abstract conceptual variability associated with ill-structured domains (Spiro et al., 1988, Spiro \& Jehng, 1990).

(3) Early introduction to the complexity of knowledge domain: A common instructional approach applied to the learning process is to break a complex topic of knowledge into small conceptual units. Then comes learning these units in isolation, and then combine the units. Unfortunately, this approach tends to oversimplify and decontextualize complex material (e.g., Brown, 1989; Spiro et al., 1988). CFT recommends introducing early to the complexity of knowledge domain in a cognitively manageable manner that still reflects some of the multifaceted interactions of various conceptual elements (Spiro \& Jehng, 1990). The advanced learner is thus prepared for a deeper explication of the knowledge with further study that is not qualitatively different from the earlier instruction. 
(4) Stressing the interrelated and web-like nature of knowledge: CFT recommends a demonstration of interrelationships in multiple contexts to provide for students a flexible understanding of a complex content area. In contrast, teaching an isolated abstracted knowledge element in isolation may produce more rigid knowledge representations that limit the ability of the learners to apply the knowledge in new knowledge application situations (Bereiter \& Scardamalia, 1985; Bransford et al., 1989; Spiro et al., 1987).

(5) Recommending assembly of knowledge. In educational material based ill-structured and complex domain of knowledge, sometimes there is a germane knowledge from a variety of previously learned sources of concepts and cases that are relevant to a novel knowledge application situation. CFT recommends that learners assemble relevant abstract conceptual and case-specific knowledge components for a given knowledge application or problemsolving task. Learners assemble it without any retrieving knowledge previously treated in the human memory to adapt knowledge treatment to the new learning situation.

\section{The Hypertext Cognitive Flexibility Theory}

Recently, the application of hypertext systems in the educational contexts has attracted considerable attention (Beeman et al., 1987, 1988; Conklin, 1987; Crane \& Mylonas, 1988; Dede, 1987, 1988; Jonassen, 1986, 1988; Lehrer, 1991; Spiro \& Jehng, 1990). Whereas some hypertext programs have been used primarily as knowledge storage and access systems, other applications of this instructional technology have attempted to structure the e-learning environments with explicit instructional goals. Many of these instruction-oriented hypertext systems have been developed in complex domains and are intended for students at an advanced stage of learning (Beeman et al., 1987, 1988; Crane \& Mylonas, 1988). Cognitive flexibility hypertext theory is used to conceive learning environments based CFT (Spiro et al., 1996). Spiro and his co-workers established this model of design of the e-learning process on two main questions. The first one is that there is in domains of teaching and learning a variety of knowledge which are ill-structured. The second question is that there is a cognitive negligence of problems linked to structure of presentation of learning resources presented to students.

In cognitive flexibility hypertext theory, Spiro and his co-workers suggest allowing learners to develop through the e-learning process based cognitive flexibility theory a flexible cognitive treatment of the learning resources, and also to acquire knowledge having a structure which can be as a flexible support in the cognitive treatment of the information.

Cognitive flexibility hypertext theory is conceived by Spiro and his co-workers (1987) but it was repeated by Godshalk et al. (2004). CFT is based on presentation of flexible knowledge for students and the understanding of the abstract concepts in learning resources. It also links abstract concepts to explain all unclear information for students. According to Spiro and Jehng (1990), links between concepts and case studies, examples or projects are more easily realized by using capacity of hypertext systems, which allow connecting explicitly the information between them. The key to know how to connect the abstract concepts is to supply themes and perspectives which can be considered through learning by cases and by projects. These problems can be solved by principles of cognitive flexibility hypertext theory (Spiro et al., 1996). 
The structure of knowledge the present experimental research is based on cognitive flexibility hypertext theory. Spiro et al., (1996) indicate that the best strategies for teaching and learning ill-structured and domains of knowledge are based flexible instruction.

In reference to conception suggested by Jacobson and Spiro (1995) in cognitive flexibility hypertext theory, the structure of learning resources adopted in the present study is resumed in the following aspects:

- Learning starts with video presenting generalities of the online course.

- The abstracted concepts of the online course to be taught are presented by means of image which allows a better visibility of the unclear concepts of the online course. The image shows clearly the architecture of hierarchical navigation in the online learning resource with a random access instruction. This non-linear navigation is based on conception suggested by cognitive flexibility hypertext theory. The image allows the advancing of knowledge gathering rather than reproductive memory, to introduce at once the abstract complexity as well as complexity of domain.

- The abstract concepts presented in the image allow reaching through hypertext links treated cases, projects, other points of view, examples, Web links etc.

- The interconnection between various concepts to be studied and case studies or examples is similar to a network of complex knowledge. Indeed, knowledge of Adobe Flash online course used for the experimentation has a structure profoundly interconnected. The interconnection is realized through hypertext links of the information stored in a network of the interconnected node. The latter allows reaching texts, graphs, sounds, videos, programs and other varieties of the useful information for explaining the unclear concepts. Hypertext systems give possibility of reaching the information in an extremely flexible manner by incorporating notions of hierarchical navigation in Adobe Flash online course. The presentation of the e-learning process is based hierarchical and flexible navigation in learning resources and is suggested by cognitive flexibility hypertext theory using hypertext systems. In fact, this theory proposes that knowledge is organized in a semantic network; concepts (node) are connected by associations (Baddley, 1993; Lindsay \& Norman, 1980). Based on similarity between structure of the organization of human memory and that of hypertext system, researchers give an importance for using hypertext systems for designing structure of navigation in learning resource and indicate that learning based hypertext is superior to linear texts from effectiveness of learning point of view (Jonassen, 1991 cited in Jonassen, 1993).

- In the present study, the active pedagogy, based on active role of the student in construction of its knowledge was adopted by referring to CFT. Indeed, students have an initiative to solve learning problems. They construct their own knowledge in interaction with learning resources. The active pedagogy based on constructivist learning theory allows to create a cognitive conflict for students and to motivate them towards the acquisition of the other knowledge to be able to solve problems (exercise, project etc.).

The implementation of CFT is not a simple issue to exploit but a power of hypertext systems used to realize links between intra and inter pages is very important to design complex online 
course based on hierarchical navigation and flexible instruction (Spiro et al., 1996). The conception of learning resource based cognitive flexibility hypertext doesn't have to allow us to solve learning problems of non-structured domain only but also aims at construction of new understandings in new situations. According to the cognitive flexibility hypertext theory, the elearning resources are conceived by a way of studying concepts through a sufficient number of examples, case studies, projects, multiple points of view etc.

The figure 1 shows abstracted concepts connected to projects, case studies, examples directed to learning such as learning by cases and the illustration of concepts to facilitate learning favored by the cognitive flexibility hypertext theory. Complex and ill-structured knowledge are better acquired with multiple representations, the abstract concepts connected by means of hypertext links with cases, as well as projects and detailed examples (Jacobson \& Spiro, 1995).

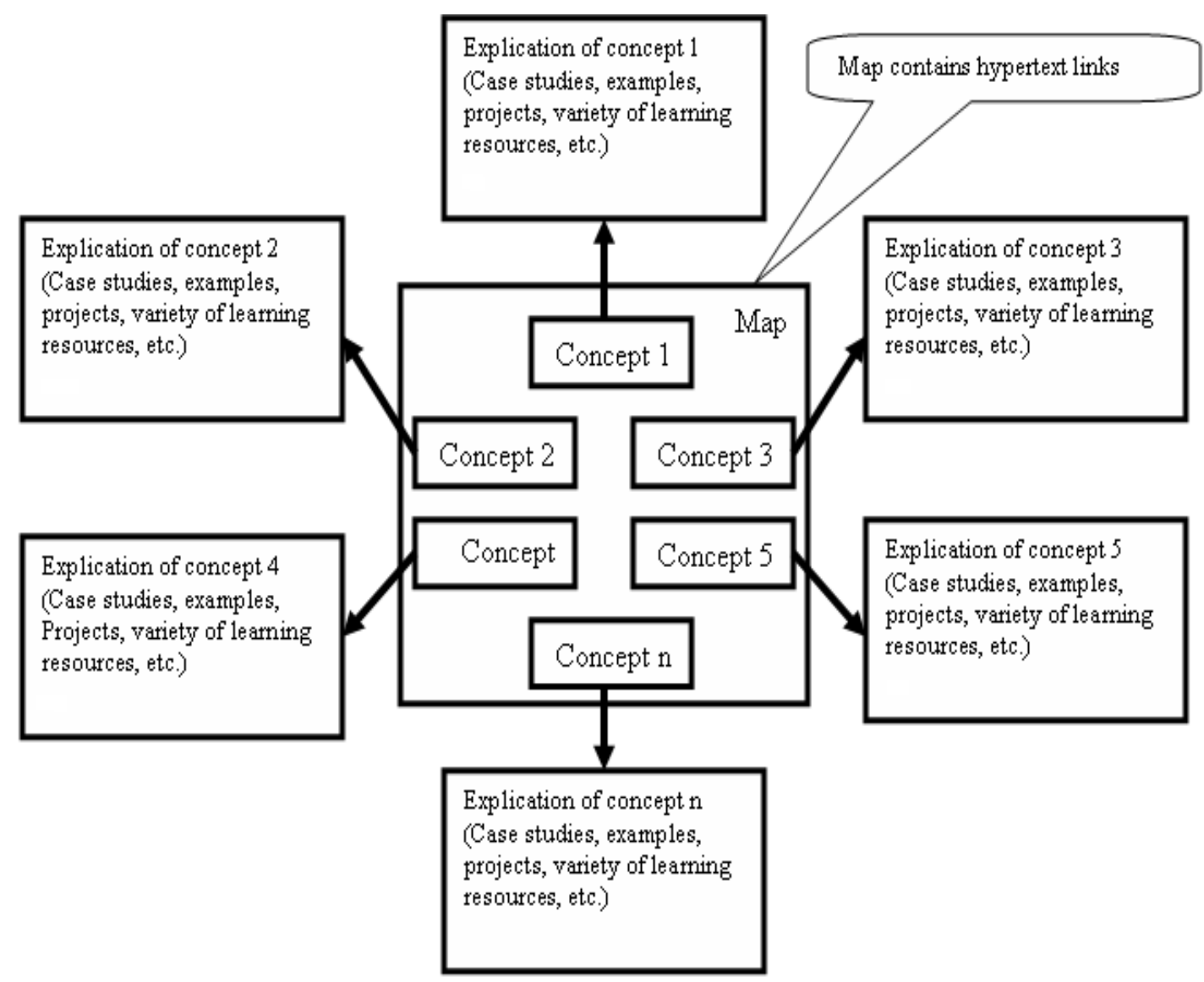

Figure 1. Conceptual Structure Based Cognitive Flexibility Hypertext Theory

\section{The Online Course Design Based Direct Instruction}

Figure 2 shows the design used by the online instructor for the e-learning process based direct instruction and used for teaching and learning the online course Adobe illustrator. 


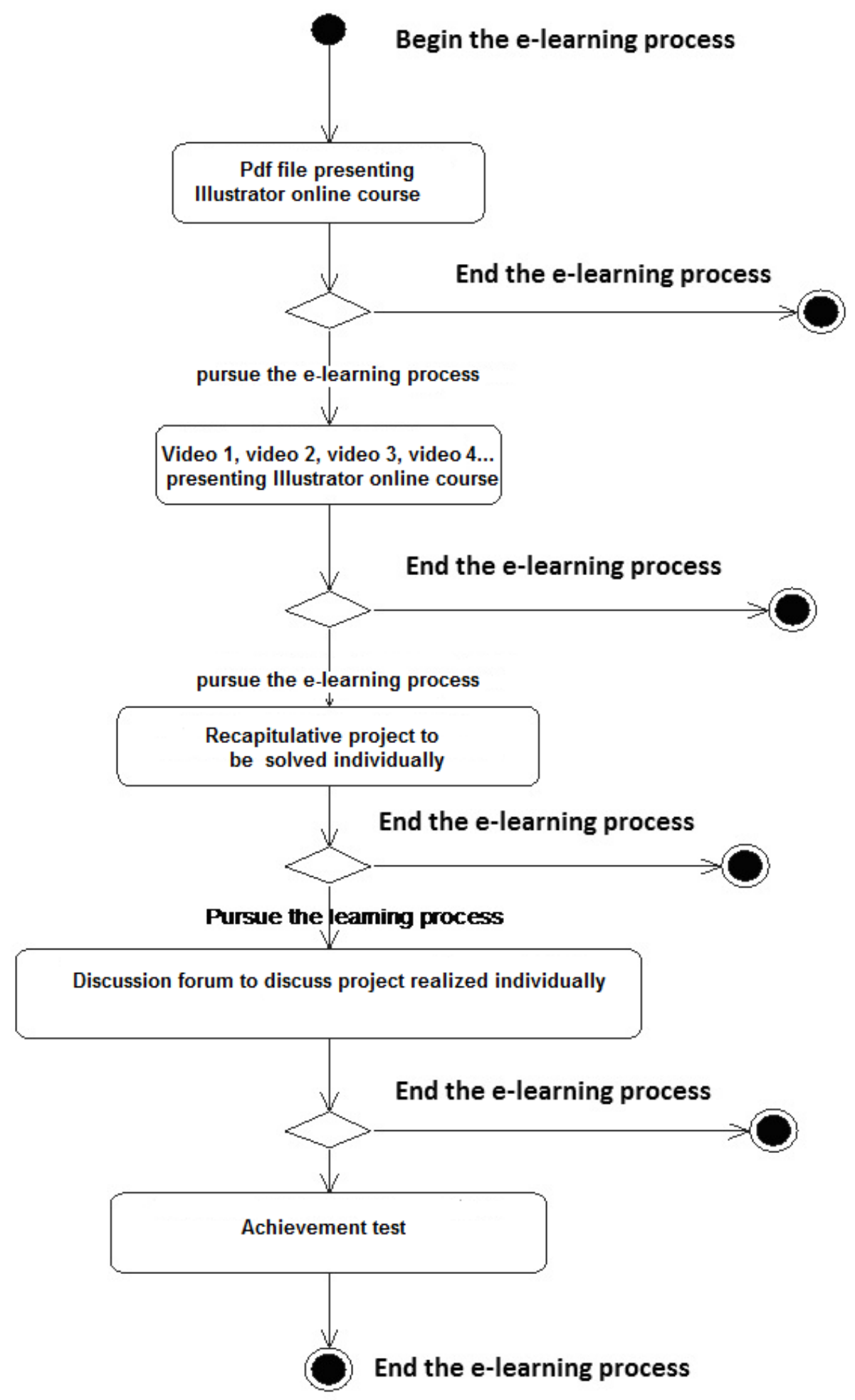

Figure 2. The Design of Direct Instruction 


\section{Implementation of the Online Course Design Based Direct Instruction}

The e-learning process based direct online course design without application of hypertext systems has the following characteristics:

- The e-learning process has a linear and not hierarchical structure. Student has to open PDF file to begin the e-learning process and to make a linear reading of the online course. The sequences of learning objects in the e-learning process are also presented linearly.

- The learning object to be taught isn't divided in some sub-objects or sections but it presented only in one PDF file.

- After reading the online course, the student has to solve the e-learning exercise individually. This problem consists of a recapitulated project of the online course taught in Moodle e-learning platform.

- After solving the e-learning exercise, students have to participate in a discussion forum to discuss the exercise which was individually solved to construct new knowledge;

- After discussions between students about exercise solved individually, they have to answer tests of knowledge acquired during the e-learning process through multiple choices questions;

- The e-learning process isn't based on hypertext structure.

Figure 3 shows an implementation of the e-learning process adopted for teaching the online course Adobe Illustrator based direct instructional design.

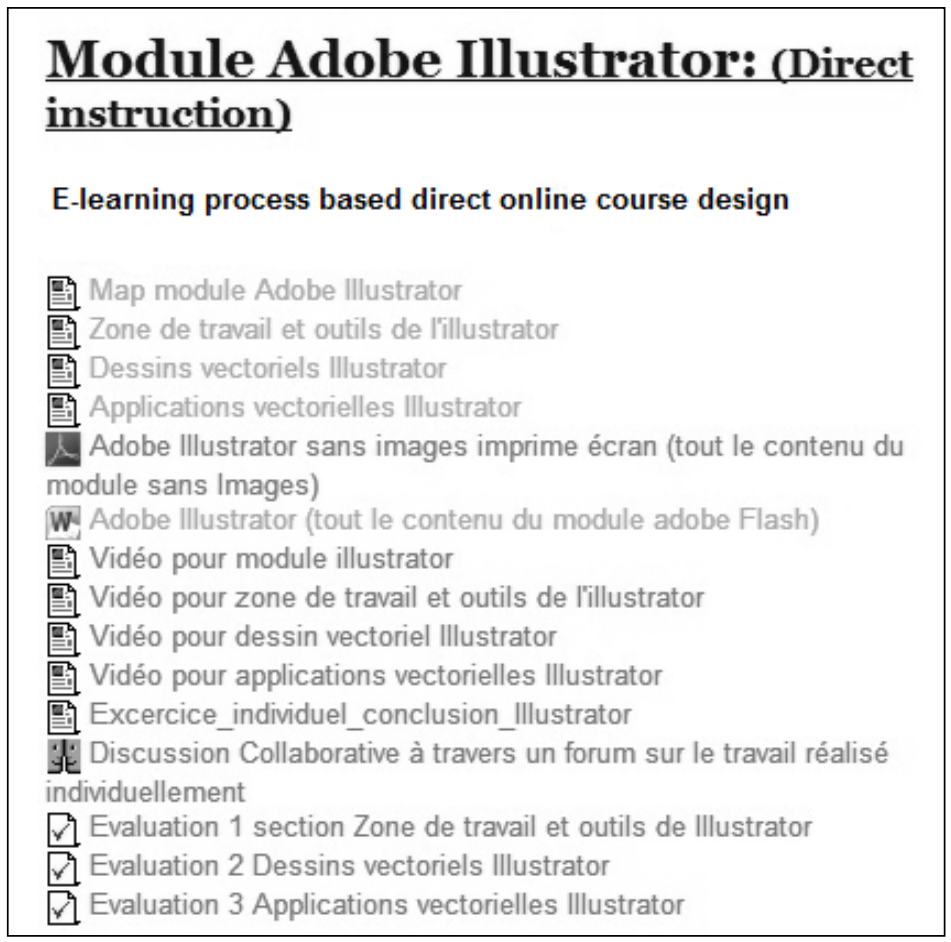

Figure 3. Implementation of Direct Online Course Design 
Design of the e-Learning Process Based Flexible Instruction and Favoring Cognitive Flexibility Hypertext Theory

Figure 4 shows the design used for construction of the new e-learning process based flexible instruction with application of hypertext systems and favoring cognitive flexibility hypertext theory.

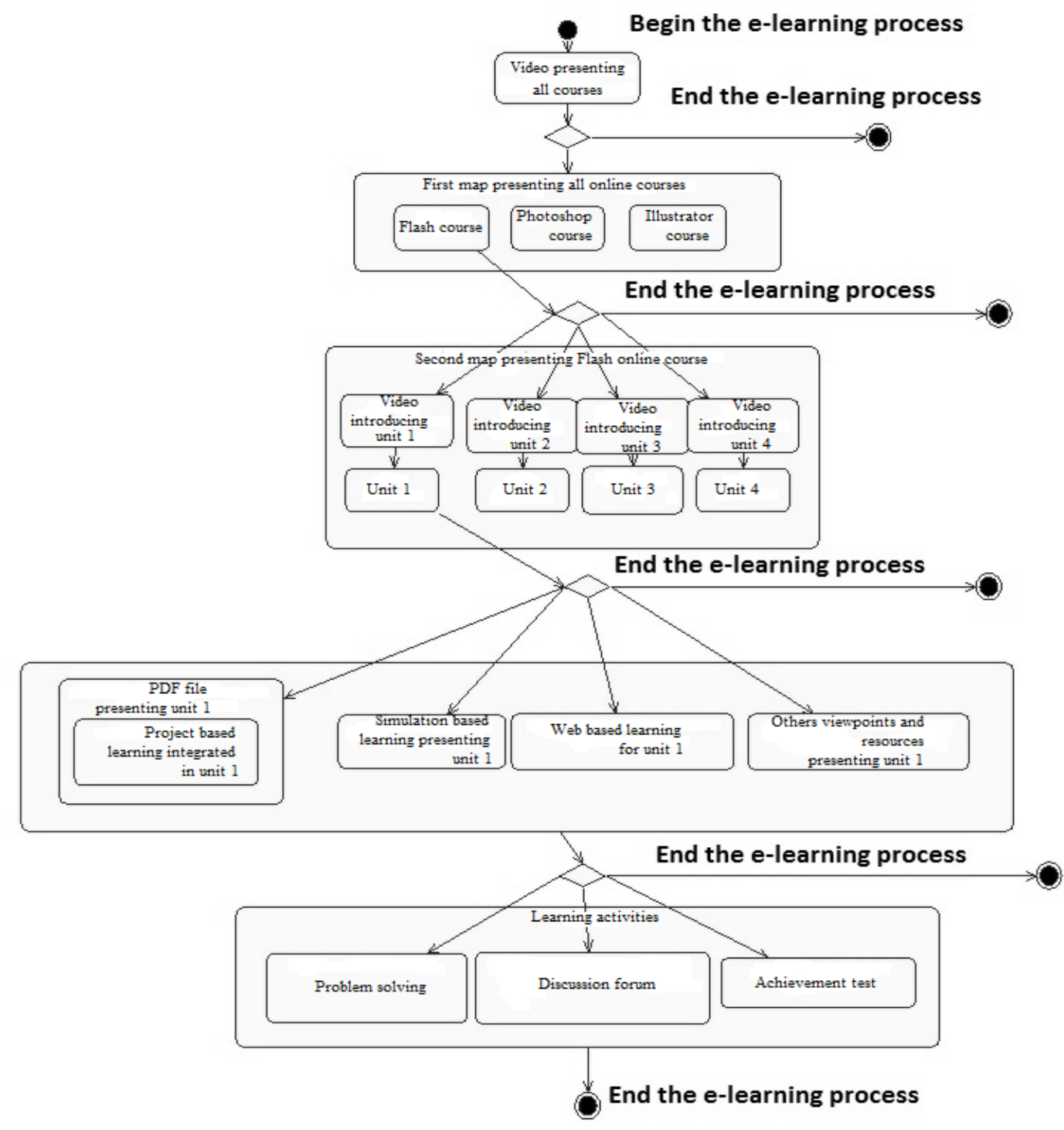

Figure 4. The Flexible Online Course Design Based Hypertext Systems

\section{Implementation of the e-Learning Process Based Flexible Online Course Design}

The e-learning process based cognitive flexibility theory use video files, PDF files, images, simulations, and discussion forums. Multiple choice questions were inserted in the e-learning 
process based hypertext systems. The implemented e-learning process has the following characteristics:

- The e-learning process contains multiple representations of knowledge through image, video, PDF, simulation, and Flash animation.

- The e-learning process contains a demonstration of the abstract interconnection similar to a network of complex knowledge.

- The abstract concepts are interconnected in order to show knowledge in use.

- The gathering of knowledge is more advanced than reproductive memory.

- The conceptual complexity and complexity of domain are introduced at once.

- Promote active learning for students.

- Design of the e-learning process is based on hierarchical rather than linear design.

- Learning resources are based hypertext and hypermedia in reference to the conception suggested by cognitive flexibility theory.

- The division of main module into several sub- modules.

- Guiding of online students during the e-learning process.

- The e-learning process allows a better cognitive legibility for student.

- The e-learning process is well structured.

Figure 5 is an implementation of the e-learning process based flexible instruction.

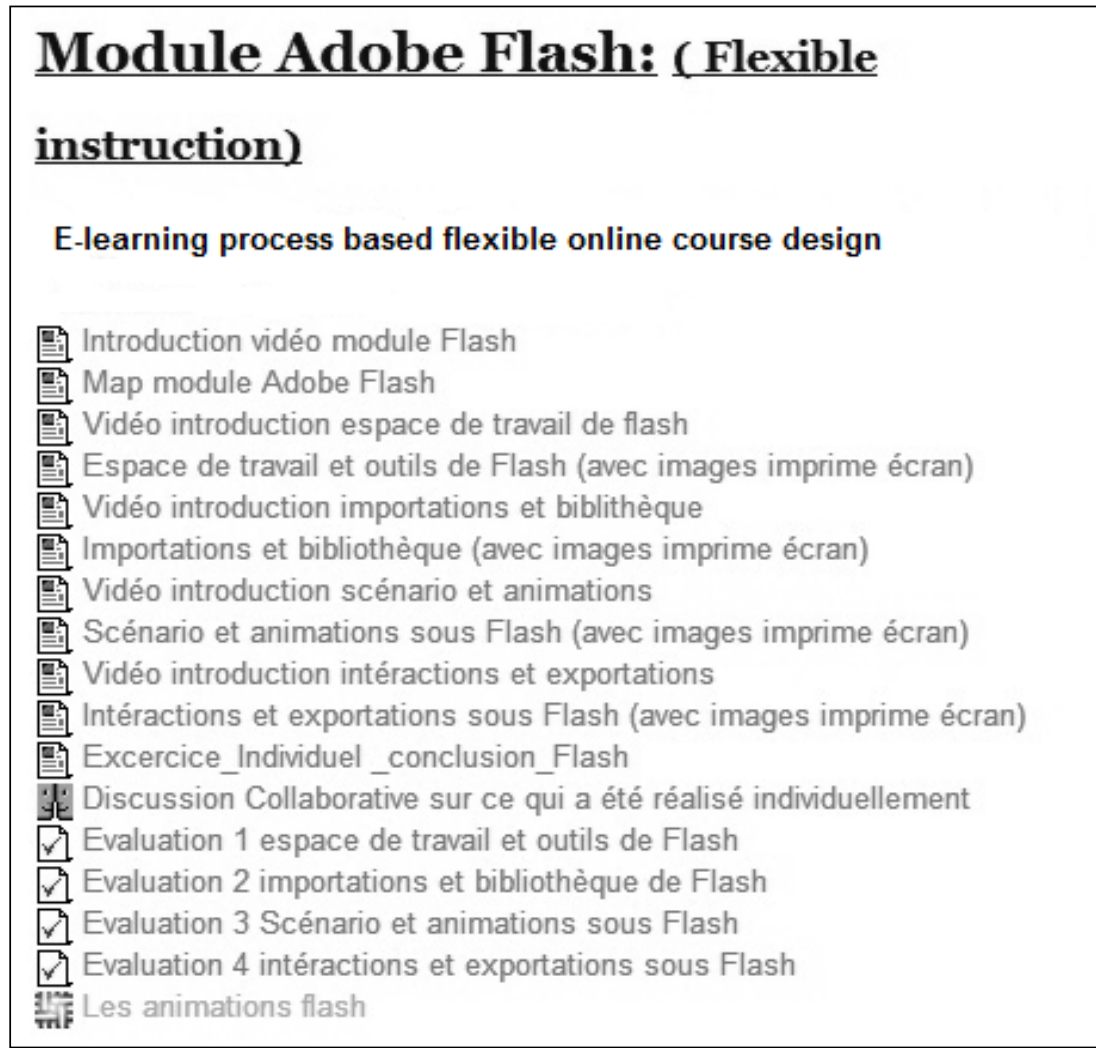

Figure 5. Implementation of the e-Learning Process Based Flexible Instruction 
Figure 6 shows that the abstracted concepts of Adobe Flash online course to be taught are presented by means of map which allows a better legibility of concepts to be explained through hypertext links.

The interconnection between various concepts to be explained through case studies, projects, other points of view, examples, Web links etc., is similar to a network of complex knowledge. Indeed, knowledge acquired by students in the e-learning process is organized in a semantic network; concepts (node) are connected by associations (Lindsay \& Norman, 1980; Baddley, 1993).

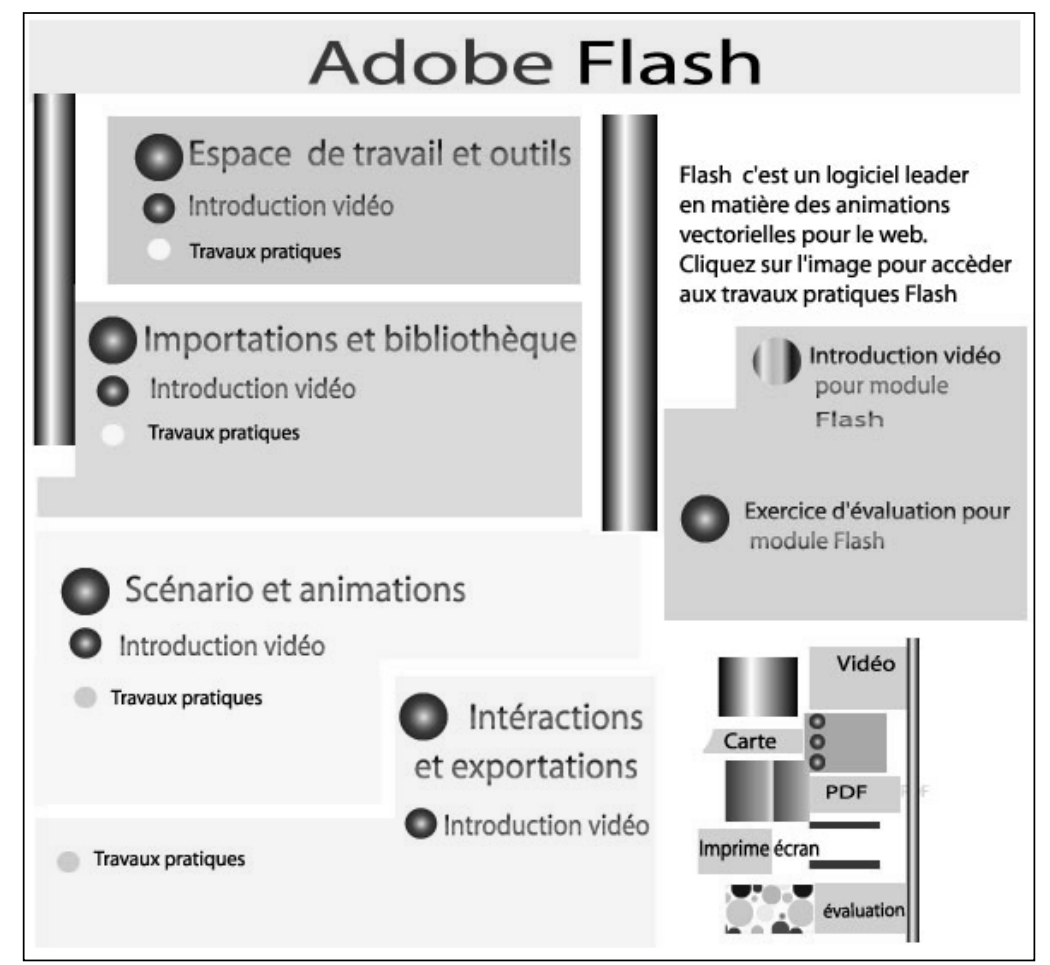

Figure 6. Map Presenting Hierarchical Navigation in the Online Course

Figure 7 shows the achievement test using Question Multiple Choices. These tests are designed by the instructor with a maximum evaluation of knowledge acquisition by students in the e-learning process. Figure 7 also shows duration of the achievement test. Generally, from our experience in teaching students in different modules of multimedia development in laboratory, we see that finishing an evaluation test or learning activity in duration lower than the one proposed by the instructor with a right answer is an indicator of a good cognitive performance for students. It shows that they acquired sufficient knowledge in learning process for answering the achievement test within prescribed time interval. Time interval of the achievement test proposed by the instructor for finishing one test is 10 minutes. 


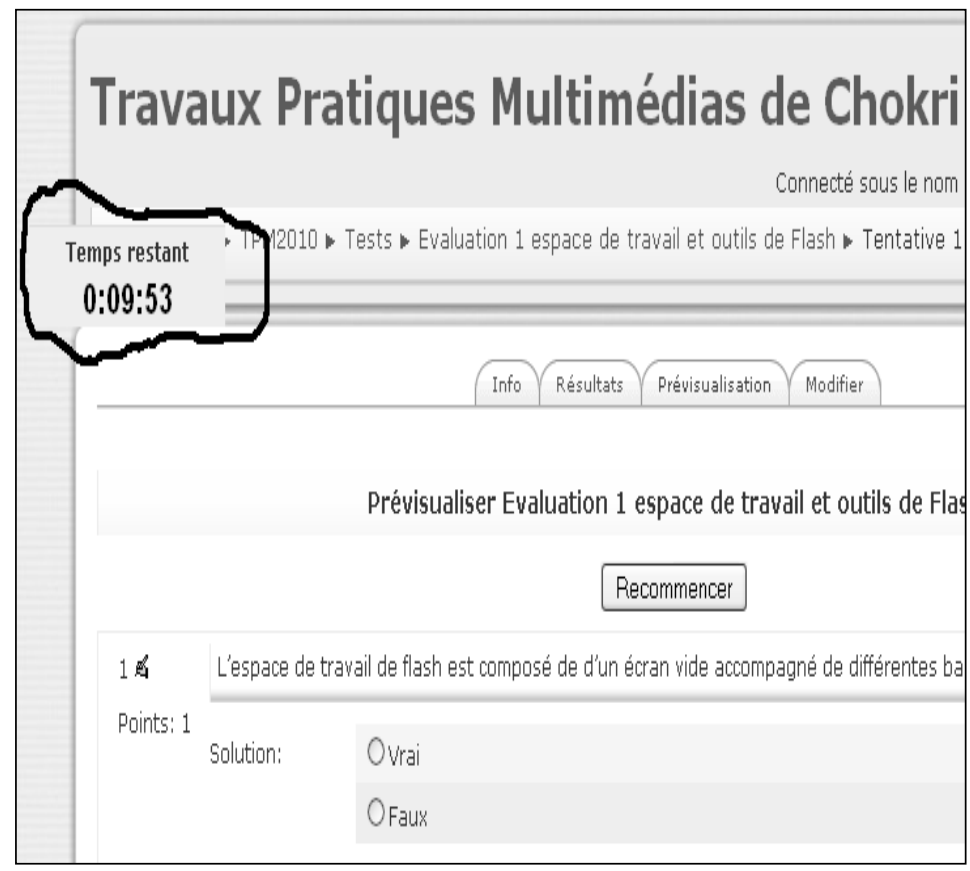

Figure 7. Print Screen Showing a Time Spent for an Achievement Test

\section{Research Hypotheses and Aims of the Study}

Cognitive flexibility hypertext theory is a theory of design of the instruction that needs to be experimented in different e-learning processes in order to know its effectiveness for online learning and teaching and then to use it in future e-learning situations (Jacobson \& Spiro, 1995). The objective of the present experimental research is to explore the effectiveness of instructional design oriented hypertext systems based cognitive flexibility hypertext theory suggested by Spiro and his co-workers to design ill-structured and complex domain of knowledge compared to direct instructional course design without hypertext systems for teaching and learning Flash online course in e-learning environment (Spiro et al., 1987).

Two hypotheses guided the present study:

Hypothesis 1: Learners of the experimental group would obtain approximately the same score, the same time of achievement test, and the same number of access to online courses as well as online activities compared to learners of control group.

Hypothesis 2: There is no difference between the experimental group and the control group at the 0.05 alpha level regarding the attitudes of online students toward the experimented elearning processes.

\section{Methods}

In the present study, the researchers employed the experimental research model searching the impact of using flexible online course design based cognitive flexibility hypertext theory compared to direct online course design before and after its experimentation with students. 


\section{Population and Sample}

The population of the present study is composed of all students of the first level of information technology diploma at the high institute of technological studies in the south of Tunisia. Researchers completed the experimentation of online course design based cognitive flexibility theory in the academic year 2010. The sample of study is composed of two groups. The first group is an experimental group and contains 73 students. In this first group, researchers applied the e-learning process based cognitive flexibility hypertext theory using hypertext systems. The second group is a control group and contains 73 students. The new online course design based cognitive flexibility hypertext is a new online course design for students. Thus, this e-learning process is experimented with an experimental group. Habitually, students use a direct online course design in e-learning environment without cognitive flexibility theory and without application of hypertext system. Thus, researchers use direct online course design without cognitive flexibility theory with the control group (73 students).

Approximately, the control group and the experimental group are similar in terms of performance in using educational technology. The achievement test is realized prior to the experimental process in order to split the sample in two similar groups from cognitive performance point of view.

Table 1 shows the results of the achievement test realized prior to the experimental process to divide a sample in two groups taking into account performance of students in achievement test. The number of students in each scale "excellent", "very good", "good", "average", "poor" is divided by 2 and one half of each scale is classified as control group and the other half is classified as the experimental group. The classification at each half in the experimental group the control group is based random method of classification.

Table 1. Results of the Achievement Test 1 Implemented Prior to the Experimentation to Divide Sample in Experimental and Control Groups

\begin{tabular}{|c|c|c|c|c|}
\hline & Frequency & Percent & Valid Percent & Cumulative Percent \\
\hline Excellent & 40 & 27.4 & 27.4 & 27.4 \\
\hline Very good & 30 & 20.5 & 20.5 & 47.9 \\
\hline Good & 14 & 9.6 & 9.6 & 57.5 \\
\hline Average & 40 & 27.4 & 27.4 & 84.9 \\
\hline poor & 22 & 15.1 & 15.1 & 100.0 \\
\hline Total & 146 & 100.0 & 100.0 & \\
\hline
\end{tabular}

\section{Data Gathering Tools}

Data gathering tools are based on tracks of online learners in the e-learning environment. Also, the survey method was used to explore the attitudes of students toward using flexible online course design.

- Tracks of online students in e-learning environment is an advantage of online teaching and learning compared to the traditional learning based presence of students in 
classrooms. Analysis of tracks of online students (Scores in achievement test, time of achievement test) provided by e-learning system is characterized by the validity and credibility and easy to export from the e-learning system for analysis. In the present study the cognitive performance of students (measurement of time answering questions, scores of achievement test, tracks of access of students to online course and activities) were provided by Moodle platform after the experimental period.

- The survey method was constructed after a content validity with a group of teachers at the institute to evaluate the attitude of online students of the experimental group toward using the new online course design based cognitive flexibility hypertext and with application of hypertext systems. The same scale is used to evaluate the attitudes of online students of the control group using direct online course design without any hypertext systems. In the present study, the attitudes of students is based (ease of learning, solving learning difficulties, guiding students in the e-learning process, structuring of the learning resource, sufficiency of time for achievement test, memorization of knowledge by student, general satisfaction of student).

\section{Justification of Measures}

Criteria of cognitive performance and statistics of the access of students to the e-learning environment were provided by the e-learning system after the experimental period. From the first day of the experimentation, students received sufficient information in using e-learning environment for effective use of Moodle e-learning platform. The following criteria are used for evaluation of the experimentation.

- The cognitive performance of students in the e-learning environment is used for acceptance or rejection of hypotheses 1 . It is based on time of achievement of learning activities. Ordinary, an elevated time of the achievement of the e-learning activity with a wrong answer of questions is an indicator of bad cognitive performance. The low time of the achievement of tests with a right answer is an indicator of a good cognitive performance of students. These ideas of cognitive performance are indicated by Spiro and his co-workers in cognitive flexibility theory (Spiro, 1996). Cognitive performance is also based on achievement test of students and their statistics of the access to the elearning platform and to learning resources and activities. Tracks of students in elearning environment were provided by Moodle e-learning system at the end of the experimental period. Statistics of the access of students to the e-learning environment and to different learning objects and activities and the number of participation of students in the online discussion are important to give ideas about student motivation in e-learning processes.

- The attitudes of students toward using the online course design based cognitive flexibility hypertext theory and direct online course design is used for acceptance or rejection of hypotheses 2 . It is an important indicator to explain the importance of the adopted instructional design for the online course. In the present study, the attitudes of students of control and experimental groups are based on survey method. The scale was distributed face-to-face and explored the attitudes of students toward direct and flexible online course design. For construction of the scale, researchers used the Likert approach (1932). Likert scale is a psychometric scale commonly used in research that investigates attitudes. When responding to a Likert scale item, respondents specify their level of agreement or disagreement on a symmetric "agree-disagree" spectrum 
for a series of statements. In the present study, researchers used a format of a typical three-level Likert items, for example, it could be: (Agree, Neutral, Disagree). Scores on responses are based on Likert scale.

For the analysis of data obtained, the Statistical Package for Social Sciences (SPSS) was used. In reporting findings, the results of both descriptive (i.e. frequency distribution and percentages) and inferential statistics (i.e. t-test) were presented.

\section{The e-Learning Environment}

The experimentation of the e-learning processes is realized in Moodle e-learning platform of Macerata University in Italy. Students received a username and a password from the online instructor to enter to the e-learning system at the URL address: http://moodle.unimc.it (Use Internet Explorer and enter the accesses code: "username: hostname; password: hostname " and then access to: "Cours Licence Multimédia" and choose "Travaux pratiques multimédia de Chokri Barhoumi". All videos inserted in flexible online course design are hosted in a server in Bologna (Italy) and they are downloaded directly from this online server at the URL address of http://flash1-bo1.unimc.it/streamings/_tunisia/

\section{Description of the Online Courses}

The online courses of Adobe Flash and Adobe Illustrator are both taught by the online instructor to help students to know how to prepare a Flash animation or vectored drawing in order to export them to web sites or interactive multimedia applications (online course, interactive website etc.). The experimented online courses are almost similar from the ease of learning, complexity of knowledge, the ill-structuring of knowledge domains etc.

The online course experimented in case of the e-learning process based cognitive flexibility hypertext theory is Adobe Flash. The online course of adobe Flash is taught in a full semester (3 months) and divided into 4 units which are:

- Workspace and tools of Adobe Flash;

- Import and library;

- Scenario and animation of Adobe Flash;

- Interactions and exports of Adobe Flash.

The online course experimented in case of the e-learning process based direct instruction is Adobe Illustrator. This online course is a part of multimedia practical courses. Adobe Illustrator is taught in a full semester ( 3 months) and it is divided into 3 units which are:

- Working zone and tools of Adobe Illustrator;

- Vectored Drawing of Adobe Illustrator;

- Some Illustrator applications. 


\section{Findings}

\section{Results of the Cognitive Performance}

\section{Time on Achievement Tests}

Table 2 shows the average time in minutes to answer the achievement tests of every learning process. This time is controlled by the e-learning system and showed to students on the screen. All times spent on achievement tests are provided by the e-learning platform and the researchers then calculated the average time of achievement tests for each online course design.

Table 2. The Average Time of Answering Questions for Each Group

\begin{tabular}{|c|c|c|c|c|c|c|c|}
\hline Online course design & \multicolumn{4}{|c|}{$\begin{array}{l}\text { The online course design based } \\
\text { flexible instruction }\end{array}$} & \multicolumn{3}{|c|}{$\begin{array}{l}\text { The online course design } \\
\text { based direct instruction }\end{array}$} \\
\hline Groups & \multicolumn{4}{|c|}{ Experimental group } & \multicolumn{3}{|c|}{ Control group } \\
\hline Tests & Test 1 & Test2 & Test 3 & Test 4 & Test 5 & Test 6 & Test7 \\
\hline $\begin{array}{l}\text { Average time of answering } \\
\text { achievement tests of every } \\
\text { online course in minutes }\end{array}$ & \multicolumn{4}{|c|}{6.18} & \multicolumn{3}{|c|}{7.51} \\
\hline $\begin{array}{l}\text { Time proposed for the } \\
\text { achievement of one test }\end{array}$ & \multicolumn{7}{|c|}{10 minutes } \\
\hline
\end{tabular}

The average time of answering the questions on achievement tests of the e-learning process based on direct online course design is 6.18 minutes. The average time of answering the questions on achievement tests of the e-learning process based flexible online course design is 7.51 minutes. The time proposed by the online instructor to complete one test is 10 minutes (Table 2). The average time of answering the achievement tests of flexible online course design are lower than the average time of answering the achievement tests of direct online course design.

\section{Number of the Answers Exceeding the Time (10 Minutes) for in Group}

Table 3 shows the average number of tests items which exceeded the time proposed by the online instructor (10 Minutes) for the achievement tests of every learning process for the experimental group and the control group. The time proposed by the instructor to achieve each test is 10 minutes in two experimented e-learning processes, but there exists some students both in the experimental or the control group who exceeded the time proposed (10 minutes) for every achievement test, taking into account that all achievement tests are designed with a manner allowing a maximum testing of knowledge acquired during the elearning process. 
Table 3. Averages of the Number of Test Items Which Exceeded Time Proposed for Each Test (10 Minutes) in Each Group

\begin{tabular}{|c|c|c|c|c|c|c|c|}
\hline $\begin{array}{l}\text { The online course } \\
\text { design }\end{array}$ & \multicolumn{4}{|c|}{$\begin{array}{l}\text { The online course design based } \\
\text { flexible instruction }\end{array}$} & \multicolumn{3}{|c|}{$\begin{array}{l}\text { The online course design } \\
\text { based direct instruction }\end{array}$} \\
\hline Groups & \multicolumn{4}{|c|}{ The experimental group } & \multicolumn{3}{|c|}{ Control group } \\
\hline Tests & Test 1 & Test 2 & Test 3 & Test 4 & Test 5 & Test 6 & Test 7 \\
\hline $\begin{array}{l}\text { Average number of } \\
\text { tests items exceeding } \\
\text { time ( } 10 \text { minutes) }\end{array}$ & \multicolumn{4}{|c|}{8} & \multicolumn{3}{|c|}{17,33} \\
\hline
\end{tabular}

\section{Scores of Students in the Achievement Tests for in Group}

Table 4 shows the averages of scores in the achievement tests for every group.

Table 4. The Average of scores in the achievement tests for each group

\begin{tabular}{|c|c|c|c|c|c|c|c|}
\hline The online course design & \multicolumn{4}{|c|}{$\begin{array}{c}\text { The online course design based } \\
\text { flexible instruction }\end{array}$} & \multicolumn{3}{|c|}{$\begin{array}{l}\text { The online course design } \\
\text { based direct instruction }\end{array}$} \\
\hline Groups & \multicolumn{4}{|c|}{ The experimental group } & \multicolumn{3}{|c|}{ Control group } \\
\hline Tests & Test 1 & Test2 & Test 3 & Test 4 & Test 5 & Test 6 & Test7 \\
\hline $\begin{array}{l}\text { The average scores of } \\
\text { achievement tests }\end{array}$ & \multicolumn{4}{|c|}{$76 \%$} & \multicolumn{3}{|c|}{$59 \%$} \\
\hline
\end{tabular}

\section{NUmbers of Students Having Right Answers of $\mathbf{1 0 0}$ Percent for in Group}

Table 5 shows the average of number of students giving the right answer to every achievement test inserted at the end of each online course design for each group.

Table 5: Average Number of Students Having Right Answers with 100 Percent Accuracy in Each Group

\begin{tabular}{|c|c|c|c|c|c|c|c|}
\hline The online course design & \multicolumn{4}{|c|}{$\begin{array}{l}\text { The online course design based } \\
\text { flexible instruction }\end{array}$} & \multicolumn{3}{|c|}{$\begin{array}{l}\text { The online course design } \\
\text { based direct instruction }\end{array}$} \\
\hline Groups & \multicolumn{4}{|c|}{ The experimental group } & \multicolumn{3}{|c|}{ Control group } \\
\hline Tests & Test 1 & Test2 & Test 3 & Test 4 & Test 5 & Test 6 & Test7 \\
\hline $\begin{array}{l}\text { Average number of } \\
\text { students having a score of } \\
100 \% \text { on the achievement } \\
\text { tests }\end{array}$ & \multicolumn{4}{|c|}{23,50} & \multicolumn{3}{|c|}{13,66} \\
\hline
\end{tabular}

\section{Accesses of Students to the Online Courses in Each Group}

Table 6 shows the access numbers of students to the e-learning resource of each learning process implemented with each group during the period of experimentation. 
Table 6. Access Numbers of Students of the Experimental Group and the Control Group to Online Courses

\begin{tabular}{|l|c|c|c|c|c|}
\hline $\begin{array}{l}\text { The online course } \\
\text { design }\end{array}$ & \multicolumn{3}{|c|}{$\begin{array}{c}\text { The online course design based } \\
\text { flexible instruction }\end{array}$} & $\begin{array}{c}\text { The online course design } \\
\text { based direct instruction }\end{array}$ \\
\hline Groups & \multicolumn{4}{|c|}{ The experimental group } & Control group \\
\hline Online courses & Unit 1 & Unit 2 & Unit 3 & Unit 4 & Course of direct instruction \\
\hline Number of access & 660 & 466 & 441 & 385 & 192 \\
\hline $\begin{array}{l}\text { Rate of access to } \\
\text { learning units }\end{array}$ & 9.04 & 6.38 & 6.04 & 5.27 & 2.63 \\
\hline Average rate of access & \multicolumn{7}{|c|}{6.68} & & 2.63 \\
\hline
\end{tabular}

\section{Accesses of Students to the Learning Activities}

Table 7 shows the access numbers of students of the experimental and control group to the elearning activities of each online course during period of experimentation.

Table 7. Tracks of Access of Students in Each Group to the E-Learning Activities

\begin{tabular}{|c|c|c|c|c|}
\hline The online course design & \multicolumn{2}{|c|}{$\begin{array}{l}\text { The online course design } \\
\text { based flexible instruction }\end{array}$} & \multicolumn{2}{|c|}{$\begin{array}{l}\text { The online course design } \\
\text { based direct instruction }\end{array}$} \\
\hline Groups & \multicolumn{2}{|c|}{ Experimental group } & \multicolumn{2}{|c|}{ Control group } \\
\hline Learning activities & $\begin{array}{l}\text { Individual } \\
\text { exercice }\end{array}$ & $\begin{array}{c}\text { On-line } \\
\text { discussion forum }\end{array}$ & $\begin{array}{l}\text { Individual } \\
\text { exercice }\end{array}$ & $\begin{array}{c}\text { On-line } \\
\text { discussion forum }\end{array}$ \\
\hline Number of access & 304 & 1232 & 200 & 442 \\
\hline Rate of access by student & 4.16 & 16.87 & 2.74 & 6.05 \\
\hline $\begin{array}{l}\text { Average of rate of access } \\
\text { by student }\end{array}$ & \multicolumn{3}{|c|}{7.92} & 6.05 \\
\hline
\end{tabular}

\section{Validation or Rejection of the First Hypothesis from the Results of Cognitive Performance}

Hypothesis 1: Learners of experimental group would obtain approximately the same score and the same amount of time on achievement test and the same number of access to the online courses and online activities compared to learners of the control group.

The average of the time on achievement tests of the experimental group is 6.18 minutes and this is better then the average time of achievement test of the control group that is 7.51 minutes. Based on the value of the time suggested by online instructor (10 minutes) to finish one test and based on scores on achievement test of the experimental group (76\%) and of the control group (59\%), we deduced that students of the experimental group using online course design based cognitive flexibility hypertext theory acquired more knowledge from the online course than students of the control group using online course design without cognitive flexibility hypertext theory. Results of the time spent to answer achievement tests shows that 
only 8 students exceeded the time of 10 minutes suggested by online instructor for answering one test, but this is 17 students for the control group. Also, the results of the number of answers obtaining a score of $100 \%$ on achievement test are higher in the case of experimental group ( 23 answers) than the case of control group (13 answers). The average rate of access of online students in experimental group to online course is 6.38 and this is higher than the average rate of access of students in the control group which is 2.67. Also, the rate of access of students to learning activities is higher in case of the experimental group (7.92) compared to the control group (6.05).

All these results of cognitive performance of online students reject the Hypothesis 1 . Learners of the experimental group don't obtain the same score and the same amount time on achievement tests and the same number of access to the online courses and online activities compared to learners of control group.

\section{Attitudes of Students toward Flexible Online Course Design and Direct Online Course Design}

ALikert type scale was implemented to explore the attitudes of students of experimental and control group toward the use of flexible online course design and direct online course design.

Table 8 shows variables used for the evaluation of attitudes of students toward using flexible online course design and direct online course design. This table also shows items adopted for each variable and values attributed for each item in each variable in the attitudes of students toward using the experimented online courses design, this value for each item (Agree, Neutral, Disagree) is respectively $(1,2,3)$. The sum of all values for items chosen for each variable is presented in the table of student attitudes for the experimental group and the control group toward using flexible or direct online course design.

Table 8. Structure of the Attitude Scale of Students in the Experimental and the Control Groups

\begin{tabular}{|c|c|c|}
\hline \multirow{2}{*}{$\begin{array}{ll}\text { Variables } \\
\end{array}$} & \multicolumn{2}{|c|}{$N=146$} \\
\hline & Items & Attributed value \\
\hline \multirow{3}{*}{$\begin{array}{l}\text { I believe that learning with the use of this } \\
\text { online course is easy. }\end{array}$} & I agree & 1 \\
\hline & Neutral & 2 \\
\hline & I disagree & 3 \\
\hline \multirow{3}{*}{$\begin{array}{l}\text { I believe that learning difficulties are solved } \\
\text { with the use of this online course. }\end{array}$} & I agree & 1 \\
\hline & Neutral & 2 \\
\hline & I disagree & 3 \\
\hline \multirow[t]{3}{*}{ I believe that I'm guided by this online course. } & I agree & 1 \\
\hline & Neutral & 2 \\
\hline & I disagree & 3 \\
\hline \multirow{3}{*}{$\begin{array}{l}\text { I believe that the e-learning resource is } \\
\text { structured. }\end{array}$} & I agree & 1 \\
\hline & Neutral & 2 \\
\hline & I disagree & 3 \\
\hline \multirow{3}{*}{$\begin{array}{r}\text { I believe that time of achievement of learning } \\
\text { activities is sufficient. }\end{array}$} & I agree & 1 \\
\hline & Neutral & 2 \\
\hline & I disagree & 3 \\
\hline
\end{tabular}




\begin{tabular}{|c|c|c|}
\hline \multirow{3}{*}{$\begin{array}{l}\text { I believe that I memorize knowledge through } \\
\text { this online course. }\end{array}$} & I agree & 1 \\
\hline & Neutral & 2 \\
\hline & I disagree & 3 \\
\hline \multirow{3}{*}{$\begin{array}{r}\text { This online course provides for me a cognitive } \\
\text { legibility. }\end{array}$} & I agree & 1 \\
\hline & Neutral & 2 \\
\hline & I disagree & 3 \\
\hline \multirow[t]{3}{*}{ Generally, I'm satisfied by this online course. } & I agree & 1 \\
\hline & Neutral & 2 \\
\hline & I disagree & 3 \\
\hline
\end{tabular}

\section{Graphic of the Attitudes of Students of Control Group towards Direct Online Course Design}

Figure 8 shows the results of the attitudes of students of control group taught with an online course based direct instruction. The graph shows different values of attitudes of students of control group. These values are the sum of different values attributed to the items (I agree, Neutral, I disagree) chosen by student for each variable in the attitude.

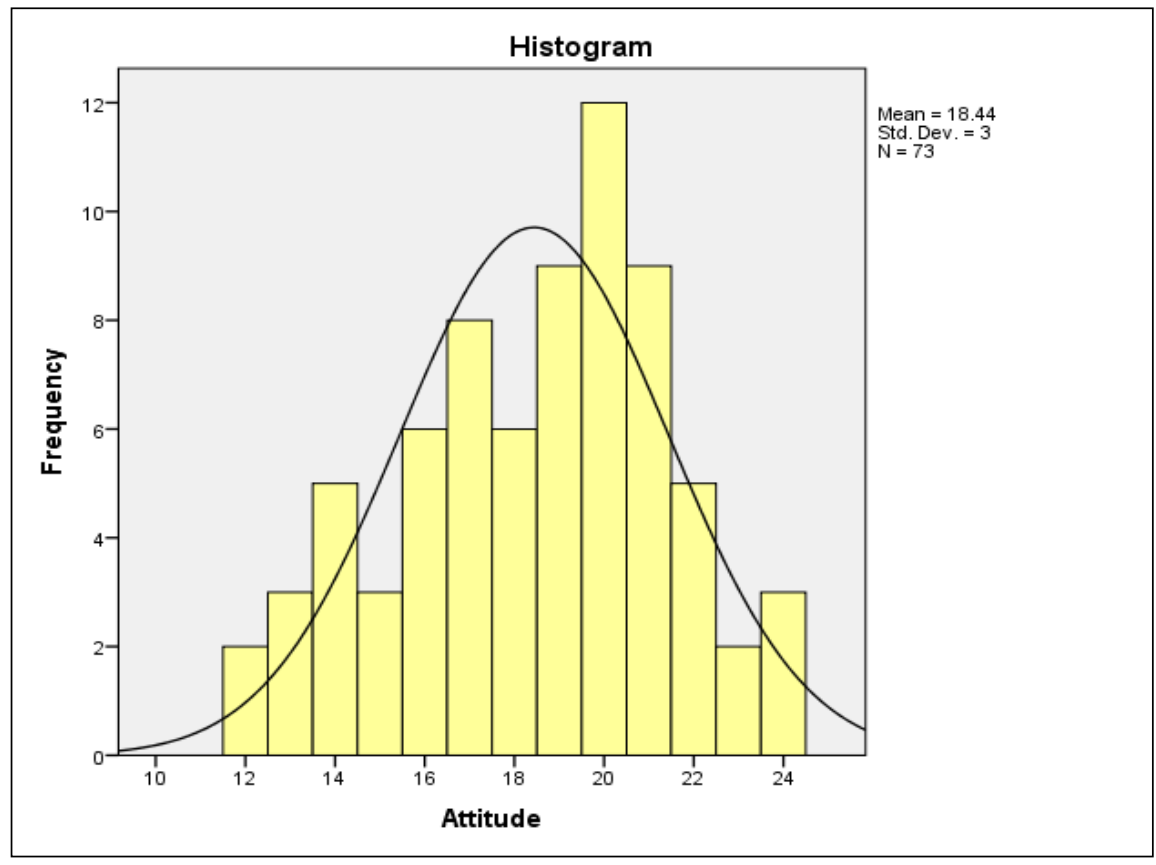

Figure 8. Attitudes of Students of Control Group towards Using Direct Online Course Design

\section{Graphic of the Attitudes of Students of Experimental Group towards Flexible Online Course Design}

Figure 9 shows results of the attitudes of students of the experimental group taught with an online course based cognitive flexibility hypertext theory. The graph shows different values of attitudes of learners of experimental group. 


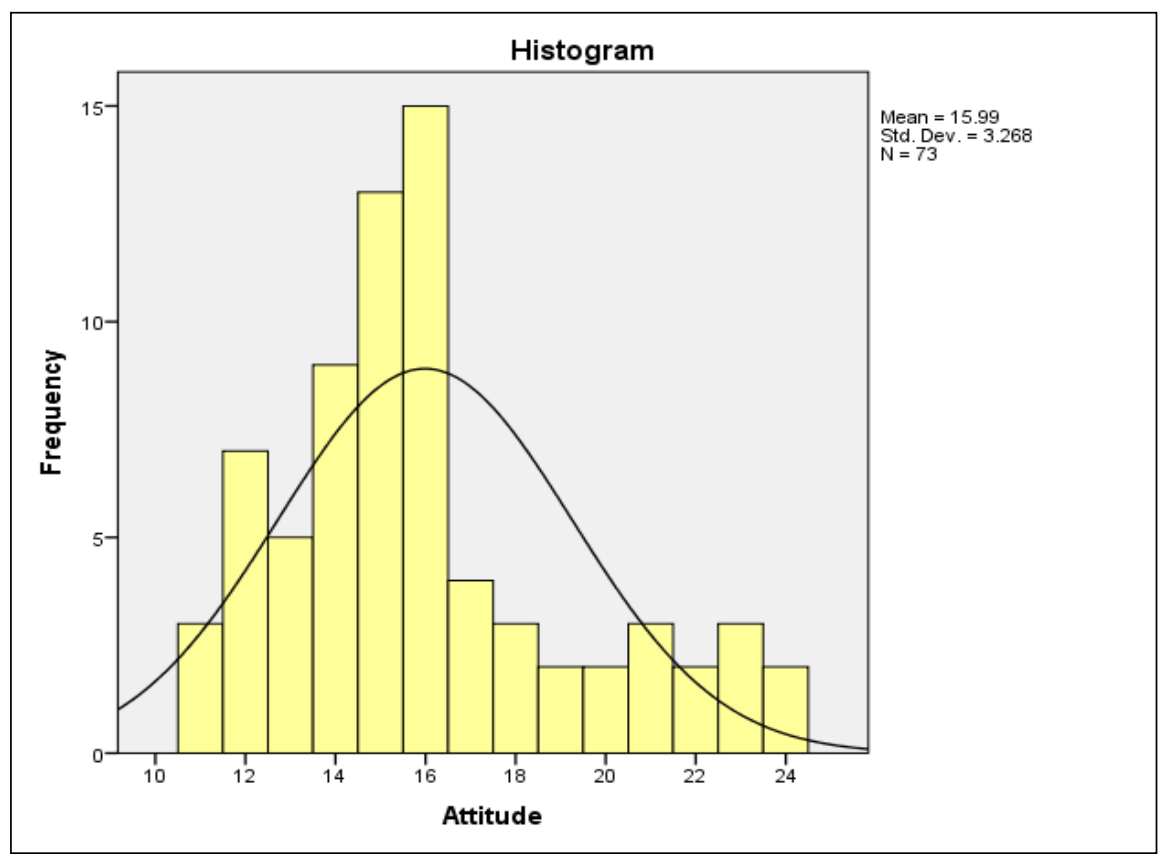

Figure 9. Attitudes of Students of Experimental Group towards Using Flexible Online Course Design

\section{Means of Group Statistics and t-Test for Equality of Means}

Table 9 shows means and standard deviations of the experimental group and the control one.

Table 9. Means of Control and Experimental Group Statistics in the Attitudes of Students

\begin{tabular}{|l|c|c|c|c|}
\hline Group & $N$ & Mean & Std. Deviation & Std. Error Mean \\
\hline Control group & 73 & 18.44 & 3.000 & .351 \\
\hline The experimental group & 73 & 15.99 & 3.268 & .383 \\
\hline
\end{tabular}

Table 10 shows t-test results of equality of means regarding the attitudes of students of the experimental group and the control group. The interpretation of the equality of means in terms of attitudes of learners is also presented in Table 10.

Table 10. $t$-test Table for Equality of Means

\begin{tabular}{|c|c|c|c|c|c|c|c|}
\hline & \multicolumn{6}{|c|}{ t-test for Equality of Means } \\
\hline & & \multirow[t]{2}{*}{$t$} & \multirow[t]{2}{*}{$d f$} & \multirow[t]{2}{*}{$\begin{array}{c}\text { Mean } \\
\text { Difference }\end{array}$} & \multirow[t]{2}{*}{$\begin{array}{l}\text { Std. Error } \\
\text { Difference }\end{array}$} & \multicolumn{2}{|c|}{$\begin{array}{l}\text { 95\% Confidence } \\
\text { Interval of the } \\
\text { Difference }\end{array}$} \\
\hline & & & & & & Lower & Upper \\
\hline \multirow{2}{*}{ Attitude } & $\begin{array}{l}\text { Equal variances } \\
\text { assumed }\end{array}$ & 4.723 & 144 & 2.452 & .519 & 1.426 & 3.478 \\
\hline & $\begin{array}{l}\text { Equal variances } \\
\text { not assumed }\end{array}$ & 4.723 & 142.957 & 2.452 & .519 & 1.426 & 3.478 \\
\hline
\end{tabular}




\section{Validation or Rejection of the Second Hypothesis from the Results of Attitudes of Students towards Using Flexible and Direct Online Course Design}

Hypothesis 2: There is no difference between the experimental group and control group at the 0.05 alpha level regarding the attitudes of online students toward the experimented e-learning processes.

Results of the attitudes of students towards using flexible and direct online course design, showed that the mean of control group is 18.44 and the mean of the experimental group is 15.99 (see Table 9). The difference between the mean of the experimental group and the control group is obvious from Table 9. To interpret the difference between mean of the experimental group and control group, we use the obtained value of the t-test.

The obtained value of the t-test calculated for the equality of means in attitudes of students of the experimental group and the control group is 4.723 (see Table 10), and this is higher than the critical value of the t-test, which 1.962. This result shows that Hypothesis 2 is rejected and there exists a difference between the experimental group and the control group at the 0.05 alpha level in terms of attitudes of students toward using flexible online course design in online teaching and learning compared to direct online course. The attitudes of students of the experimental group are positive towards using flexible online course design than the attitudes of students of the control group towards using direct online course design. The mean of the control group is 18.44 and that of the experimental one is 15.99 . The calculation of the mean is based on the value attributed for each item; I agree: 1, Neutral: 2, I disagree: 3 (See Table 8). The mean of the experimental group is smaller than that of the control group. These results of the performed t-test for equality of means explain that students of the experimental group have more positive attitudes towards using flexible online course design. Stade differently, students of the experimental group are more satisfied by the e-learning process based flexible instruction based hypertext systems than students of the control group using direct online course design without hypertext systems.

\section{Discussion}

Results of cognitive performance of students as shown in the Table 2 have demonstrated that the e-learning process based on flexible online course design based cognitive flexibility hypertext is more effective from the cognitive performance and knowledge acquisition point of view than the e-learning process based on direct online course design without using hypertext systems. The manner of presentation of the online course for students has a cognitive impact on the effectiveness of learning. Students of the experimental group in the present study demonstrated that they are cognitively more successful in new e-learning process based on flexible instruction and hypertext systems than students of control group. The cognitive performance of the former demonstrated by less time of answering questions on the achievement tests with a high score in achievement test is an advantage of the e-learning process based on cognitive flexibility theory using hypertext systems favoring.

Results in Table 3 show that a number of students from both the control and the experimental group that are exceeding the time (10 minutes) suggested by online instructor to complete one test. Indeed, the average number of the achievement test item which exceeded the time of one test ( 10 minutes) is only 8 for the experimental group, whereas this number is 17 for 
the control group. In case of the new e-learning process based on flexible online course design, students of the experimental group more quickly answered tests with right answer; it is a good indicator of cognitive performance.

According to Table 4, the researchers noticed that the average score of students from the experimental group on achievement tests is higher than that of students of the control group. Generally, if students obtain best score on achievement test, this means that there are good results of knowledge acquisition, mainly when achievement tests such as in present study allow a maximum evaluation of knowledge acquired during the e-learning process. The good score of students of the experimental group on achievement test may indicate a good cognitive performance and knowledge acquisition and treatment by students. In fact, they cannot obtain high scores on the achievement test without better results of learning and without acquisition of knowledge through the e-learning process.

Table 5 shows that the average of right answers with score of $100 \%$ for the e-learning process of the experimental group is approximately 24 students, whereas for the control group this value is only approximately 14 students. Results clearly show the importance of the online learning process based on cognitive flexibility hypertext theory (Spiro et al., 1996) used with the experimental group compared to direct instruction without using hypertext systems used for the control group from cognitive performance and knowledge acquisition point of views.

Table 6 shows that the average rate of access of students of the experimental group to online course is higher than that of the control group. The online course design based on cognitive flexibility hypertext theory contains a demonstration of the abstract interconnection similar to a network of complex knowledge conform to the theory suggested by Spiro and his co-workers (Spiro et al., 1996). The abstract concepts are interconnected in order to show the knowledge as knowledge in uses and facilitate navigation of learners in course and unit and sub-unit of the course. In this theory of design of instruction, the online e-learning process is based hierarchical navigation and not linear learning process with dividing Flash online course in units. The implication of the cognitive flexibility theory in using hierarchical navigation with application of hypertext systems is to promote an active learning for students and motivates them to access the online course (Spiro et al., 1996). Researchers give an importance for using hypertext systems for designing structure of navigation in learning resource and indicate that learning based hypertext is superior to linear texts from effectiveness of learning point of view (Jonassen, 1991 cited in Jonassen, 1993).

Table 7 shows that the average rate of access by student to the e-learning activities (exercise activity, discussion forum etc.) is higher in case of the experimental group (7.92) than that of the control group (6.05). The e-learning process based on cognitive flexibility hypertext theory promotes an active learning for students and guide them during the e-learning process and also motivate them to access frequently to the e-learning activities.

Theoretical implication of the cognitive flexibility theory in using online course designed with respect to 5 principles of CFT which suggest a demonstration of interrelationships in multiple contexts to provide for students a flexible understanding of a complex and ill-structured knowledge. As a consequence, this allows to obtain good results of learning and improve the ability of learners to apply the knowledge in new knowledge application situations (Bereiter \& Scardamalia, 1985; Bransford et al., 1989; Spiro et al., 1987). 
The cognitive flexibility theory recommends multiple knowledge representations with using multiple ways to represent knowledge in online course design based on flexible instruction to facilitate understanding of knowledge by learners (e.g. multiple themes, multiple analogies, multiple intellectual points of view) to reflect more accurately with the multifaceted nature of complex knowledge. This instructional principle of cognitive flexibility has been applied with online course design used with experimental group and shows a good result of cognitive performance (high scores in achievement test, low average time of achievement test, less number of answers exceeding suggested time of achievement test etc.).

Cognitive flexibility hypertext theory suggested by Jacobson and Spiro $(1993,1995)$ provides multiple representations of the same knowledge to be acquired by learners and allows for them the necessary mental developments for treatment of information and knowledge acquisition.

Results of the attitudes of students towards using flexible online course design show that students of the experimental group said that the e-learning process based on cognitive flexibility hypertext facilitates learning of Adobe Flash online course. Results show that the new e-learning process based on flexible online course design has a positive impact on the facilitation of learning Adobe Flash online course. Spiro and his co-workers indicate that design of the e-learning process based on hypertext system and favoring cognitive flexibility theory makes learning easy for students (Beeman et al., 1987, 1988; Conklin, 1987; Crane \& Mylonas, 1988; Dede, 1987, 1988; Jonassen, 1986, 1988; Lehrer, 1991; Spiro \& Jehng, 1990).

In the context of the attitudes of students toward using flexible online course design, the results also show that students of the experimental group believe in the fact that the elearning process based on hypertext systems and favoring cognitive flexibility theory allows them to solve their e-learning difficulties linked to navigation into the e-learning process and learning resources. These results of the attitudes of students obtained for variable "solving learning difficulties" are confirm the idea of Spiro and his co-workers for the added value of the hypertext system in solving e-learning difficulties related to the navigation of students both into e-learning process and learning resources (Spiro et al., 1996).

Students of the experimental group agree that they are guided in the e-learning process based on hypertext systems. The e-learning process based on hierarchical navigation in the e-learning resources was guiding students to navigate in the e-learning resource and reduce cognitive load triggered by the complexity of the e-learning content (Spiro et al, 1996). Spiro et al, (1996) highlighted the importance of hierarchical navigation in the e-learning process and learning resources in guiding students for learning.

Students of the experimental group are more satisfied by the structure of the e-learning process based on hierarchical navigation and favoring cognitive flexibility hypertext theory. The clear structure of the e-learning process is a characteristic of hierarchical navigation based on the use of hypertext systems in the design of the e-learning process (Spiro et al., 1996).

Based on the results of the attitudes of students of the experimental group, it appears that students of the sample agree that the e-learning process based on hypertext systems has an added value on the effectiveness of learning. The e-learning process based on hypertext systems used for teaching and learning Adobe Flash online course helps students easily memorize knowledge useful for learning. These results are fully in agreement with the ideas of Sipro and his co-workers (1996). 
Generally, the attitudes of students of the experimental group toward using flexible online course design are positive compared to that of students of the control group toward direct online course design. Students of the experimental group are more satisfied by the e-learning process based on cognitive flexibility hypertext theory.

\section{Limitations}

One of the limitations of this study is the size of the sample. In fact, while inferential statistics were used to analyze the data and to detect significant differences between and group means, it is not advisable for the researchers to use the results from this study to generalize to larger populations of entire cultural groups. In addition, it is interesting to mention that small samples and short tests can make it more difficult to get statistically significant differences. The scale of the attitudes of students toward using flexible online course design used in this study only contained 8 items. This study is experimented in the context of the course adobe Flash and available for all Adobe products (illustrator, Photoshop, shockwave, in-design, audition, soundbooth, support advisor, master collection etc.) and must be experimented with other complex and ill-structured domains of knowledge.

\section{Conclusions}

This study has discussed the transfer of ill-structured knowledge resulting from the application of an innovative theory-based hypertext learning environment and compared to direct online course design. Results of the present study are complementary and coherent and reject the first and the second hypothesis in favor flexible instruction.

Results of the experimentation of the e-learning processes based on flexible instruction compared to the direct instruction suggest that the application of the instructional hypertext systems in the design of the online course demonstrates conceptual interrelationships and the assembly of different case studies and abstract knowledge components. It would prepare students to use their knowledge in new ways and in situations and provide the educational effectiveness of a given type of technology-based learning environment (Spiro et al., 1996).

This study can assist students in developing rich, interconnected, and usable knowledge in a wide range of domains. The effectiveness of learning is provided by the hypertext structure of presentation of the e-learning resources for online students. The deepening of abstracted concepts in case studies, examples, projects, varieties of learning resources may guide students during the e-learning process. The online course design based on cognitive flexibility hypertext theory (Spiro et al., 1996) contains a demonstration of the abstract interconnection similar to a network of complex knowledge. The abstract concepts are interconnected in order to show knowledge as "knowledge in uses." Also, the design of the e-learning process is based on hierarchical learning structure of presentation of learning resources and activities and not linear learning process. The modules are divided in sub-modules of learning. Also, the online courses are based on hypertext and hypermedia in reference to the instructional design suggested by cognitive flexibility hypertext theory (Spiro et al., 1996). The cognitive flexibility hypertext theory promotes an active learning for students and motivates them to access the online courses. 
According to the experimental results, researchers observe that cognitive flexibility hypertext theory used to design Flash online course has a remarkable positive effect on the effectiveness of learning. The cognitive performance and frequent accesses of learners to the e-learning resources and learning activities are advantages of instructional design based on CFT. The cognitive flexibility hypertext theory has an added value on the effectiveness of learning and cognitive development of students.

Cognitive flexibility theory facilitates the cognitive development useful for learning and the knowledge acquisition by students. Indeed, students can acquire a capacity to pass of a type of data processing to the other one in a faster and flexible manner. Cognitive flexibility hypertext theory used in instructional design suggests that students can face complexity of learning situation more easily with multiple representations of the same information in various contexts to acquire the necessary mental developments (Spiro et al., 1996).

Finally, the perspective of this experimental study is to create a new model of instructional design suggested by flexible instruction and learning content suggested by theories favoring the use of multimedia presentations in various learning resources such as dual coding theory and Mayer's model for cognitive treatment of multimedia objects in online courses.

\section{References}

Banzato, M. (2012). A case study of teachers' open educational practices. Journal of e-Learning and Knowledge Society, 8(3), 153-163.

Baddeley, A.D. (1993). La mémoire humaine: Théorie et pratique. Grenoble : Presses Universitaires de Grenoble.

Beeman, W. 0., Anderson, K. T., Bader, G., Larkin, J., McClard, A. P., McQuillan, P., \& Shields, M. (1987). Hypertext and pluralism: From lineal to non-lineal thinking. Hypertext ' 87 papers (pp. 67-88). Chapel Hill: University of North Carolina Press.

Beeman, W. 0., Anderson, K., Bader, G., Larkin, J., McClard, A. P., McQuillan, P., \& Shields, M. (1988). Intermedia: A case study of innovation in higher education (Final report to the Annenberg/CPBProject), Providence, RI: Brown University, Office of Program Analysis, Institute for Research and Scholarship.

Bereiter, C. \& Scardamalia, M. (1985). Cognitive coping strategies and the problem of "inert knowledge." In S. F. Chipman, J. W. Segal, \& R. Glaser (Eds.), Thinking and learning skills: Current research and open questions (pp. 65-80). Hillsdale, NJ: Erlbaum.

Bransford, J. D., Franks, J. J., Vye, N. J., \& Sherwood, R. D. (1989). New approaches to instruction: Because wisdom can't be told. In S. Vosniadou \& A. Ortony (Eds.), Similarity and analogical reasoning (pp. 470-497). Cambridge: Cambridge University Press.

Brown, A. L. (1989). Analogical learning and transfer: What develops? In S. Vosniadou, \& A. Ortony (Eds.), Similarity and analogical reasoning (pp. 470-497). Cambridge: Cambridge University Press.

Coulson, R. L., Feltovich, P. J., \& Spiro, R. J. (1989). Foundations of a misunderstanding of the ultrastructural basis of myocardial failure: A reciprocation network of oversimplifications. The Journal of Medicine and Philosophy, 14, 109-146.

Conklin, J. (1987). Hypertext: An introduction and survey. IEEE Computer, 20(9), 17-41. 
Crane, G. \& Mylonas, E. (1988). The Perseus project: Interactive curriculum on classical Greek civilization. Educational Technology, 28(11), 25-32.

Dede, C. J. (1987). Empowering environments, hypermedia and micro worlds. The Computing Teacher, 15(3), 20-24.

Dede, C. J. (1988). The probable evolution of artificial intelligence based educational devices. Technological Forecasting and Social Change, 34, 115-133.

Feltovich, P. J., Spiro, R. J., \& Coulson, R. L. (1989). The nature of conceptual understanding in biomedicine: The deep structure of complex ideas and the development of misconceptions. In D. Evans \& V. Pate (Eds.), The cognitive sciences in medicine (pp. 113172). Cambridge, MA: The MIT Press (Bradford Books).

Godshalk, V. M., Douglas, M. H., \& Leslie, M. (2004). The role of learning tasks on attitude change using cognitive flexibility hypertext systems. Journal of the Learning Sciences, 13(4), 507-526.

Jonassen, D.H. (1991). Hypertext as instructional design. Educational Technology Research and Development, 39(1), 83-92.

Jonassen, D.H. \& Wang, S. (1993). Acquiring structural knowledge from semantically structured hypertext. Journal of Computer-Based Instruction, 20(1), 1-8.

Jonassen, D. H. (1986). Hypertext principles for text and courseware design. Educational Psychologist, 21, 269-292.

Jonassen, D. H. (1988). Designing structured hypertext and structuring access to hypertext. Educational Technology, 28(11), 13-16.

Jacobson, M. J. \& Spiro, R. J. (1991). A framework for the contextual analysis of computerbased learning environments (Tech. Rep. No. 527). Urbana-Champaign: University of Illinois, Center for the Study of Reading.

Jacobson, M. J. \& Spiro, R. J. (1993). Hypertext learning environments, cognitive flexibility, and the transfer of complex knowledge: An empirical investigation (Technical Report 573). Center for the Study of Reading.

Jacobson, M.J., Maouri, C., Mishra, P., \& Kolar, C. (1995). Learning with hypertext learning environments: Theory, design and research. Journal of Educational Multimedia and Hypermedia, 4, 321-364.

Lehrer, R. (1991). Authors of knowledge: Patterns of hypermedia design. Paper presented at the annual meeting of the American Educational Research Association, San Francisco.

Lindsay, P. \& Norman, D. (1980). Traitement de l'information et comportement humain. France : Etudes Vivantes.

Likert, R. (1932). A technique for the measurement of attitudes. Archives of Psychology, 140, $1-55$.

Myers, A. C., Feltovich, P. J., Coulson, R. L., Adami, J. F., \& Spiro, R. J. (1990). Reductive biases in the reasoning of medical students: An investigation in the domain of acid-base balance. In B. Bender,R. J. Hiemstra, A. J. J. A. Scherbier, \& R. P. Zwierstra (Eds.), Teaching and assessing clinical competence. Groningen, The Netherlands: BoekWerk.

Rossi, P. G. (2006). Design and ongoing monitoring systems for online education. Proceedings of On Line Educa. Berlin. 
Rossi, P.G. (2009). Ambiente di apprendimento con elementi di artificial intelligence. JE-LKS. Journal of E-Learning and Knowledge Society, 5(1), 65-75.

Rossi P. G., Carletti S., Bentivoglio, C. A., Bonura, D., Cannella, V., Pipitone, A., Pirrone, R., \& Russo, G. (2010). Intelligent Agents supporting user interactions within self regulated learning processes. JE-LKS. Journal of E-Learning and Knowledge Society, 6(2), 27-36.

Richard,H. \& Haya, A. (2009). Examining student decision to adopt web 2.0 technologies: theory and empirical tests. Journal of Computing in Higher Education, 21(3), 183-198.

Spiro, R. J., Vispoel, W. P., Schmitz, J. G., Samarapungavan, A., \& Boerger, A. E. (1987). Knowledge acquisition for application: Cognitive flexibility and transfer in complex content domains. In B. K. Britton, \& S. M. Glynn (Eds.), Executive control processes in reading (pp.177-199). Hillsdale, NJ: Erlbaum.

Spiro, R. J., Coulson, R. L., Feltovich, P. J., \& Anderson, D. K. (1988). Cognitive flexibility theory: Advanced knowledge acquisition in ill-structured domains. Tenth annual conference of the Cognitive Science Society (pp.375-383). Hillsdale, NJ: Erlbaum.

Spiro, R. J., Feltovich, P. J., Jacobson, M. J., \& Coulson, R. L. (1992). Cognitive flexibility, constructivism, and hypertext: Random access instruction for advanced knowledge acquisition in ill-structured domains. In T. M. Duffy \& D. H. Jonassen (Eds.), Constructivism and the technology of instruction: A conversation (pp.57-76). Hillsdale, NJ: Lawerence Erlbaum Associates.

Spiro, R. J., Feltovich, P. J., Jacobson, M. J., \& Coulson, R. L. (1996). Cognitive flexibility, constructivism and hypertext: Random access instruction for advanced knowledge acquisition in ill-structured domains. I Simpósio Investigação e Desenvolvimento de Software Educativo.

Spiro, R. J. \& Jehng, J. C. (1990). Cognitive flexibility, random access instruction, and hypertext: Theoryand technology for the nonlinear and multidimensional traversal of complex subject matter. In D. Nix and R. J. Spiro (Eds.), Cognition, education, and multimedia (pp.163-205). Hillsdale, NJ: Erlbaum.

Wittgenstein, L. (1953). Phylosophical investigation. New York: Macmillan.

Zengin, B., Arikan, A., Dogan, D. (2011). Opinions of English Major Students about Their Departments' Websites. Contemporary Educational Technology, 2(4), 294-307.

Correspondence: Chokri Barhoumi, Assistant Professor, Department of Educational Technology, Faculty of Education, Taibah University, Kingdom of Saudi Arabia 